\title{
The sociodemographic determinants of non- communicable diseases among the adult population of Dubai: self-reported data from Dubai household health survey, 2019
}

Wafa K. Alnakhi ( $\nabla$ wkalnakhi@dha.gov.ae)

Dubai Health Authority

Heba Mamdouh

Dubai Health Authority

Hamid Y. Hussain

Dubai Health Authority

Gamal M. Ibrahim

Dubai Health Authority

Amar Sabri Ahmad

New York University Abu Dhabi

Raghib Ali

New York University Abu Dhabi

Abdishakur Abdulle

New York University Abu Dhabi

\section{Research Article}

Keywords: chronic diseases, non-communicable diseases, sociodemographic characteristics, Dubai, complex survey design, multistage probability sampling, logistic regression model

Posted Date: February 16th, 2021

DOl: https://doi.org/10.21203/rs.3.rs-192942/v1

License: (9) This work is licensed under a Creative Commons Attribution 4.0 International License. Read Full License 


\section{Abstract}

Background: Non-communicable diseases (NCDs) are the leading causes of death worldwide. In the UAE, NCD s account for nearly $77 \%$ of all deaths. There is limited empirical research on this topic in the UAE. We aim to examine this association among the adult population in the Emirate of Dubai.

Method: This study used data from the Dubai Household Health Survey (DHHS), 2019. In this survey, 2,247 families were interviewed and only adults aged $18+$ were included for the analysis. The selfreported chronic disease was defined as reporting any chronic morbidities occurred during the past year that required ongoing medical attention and medical care. Sociodemographic characteristics covariates were age group, marital status, nationality, gender, education and working status. The quasi-binomial distribution was used to identify factors associated with chronic disease.

Results: The prevalence of chronic diseases among the adult population of Dubai was $15.01 \%$. Individuals aged 60+, local Arabs (Emirati), divorced and widowed individuals, and individuals who were not currently working reported a chronic disease more than the other groups. In the regression analysis, age (years) was the strongest predictor (OR 3.6, 95\% Cl: 2.8, 4.7). Males were more likely to report a chronic disease (OR 1.61, 95\% Cl: 1.277, 2.035). Unmarried individuals were less likely to report a chronic disease (OR $0.11,95 \% \mathrm{Cl}: 0.02,0.70)$. However, older individuals who were unmarried were more likely to report a chronic disease compared to the reference group (OR 2.8, 95\% Cl: 1.2, 6.1). Emiratis were more likely to report a chronic disease (OR $2.08,95 \% \mathrm{Cl}: 1.62,2.67)$.

Conclusion: The self-reported rate of chronic disease was shown to be higher in older individuals, males, Emiratis, and older individuals who were unmarried. This is one of the few studies related to chronic diseases in Dubai. It is important to translate the current study findings into policies to help reduce the incidence of chronic diseases in Dubai and to minimize the negative impact of these illnesses, particularly among those with the sociodemographic risk factors identified here. In addition, healthcare services and resources should be reallocated to the population groups with greater health needs.

\section{Background}

Non-communicable diseases (NCDs), also referred to as chronic diseases, are the leading cause of death worldwide. Based on WHO projections, NCDs will account for over $70 \%$ of all deaths globally by 2025 , with $85 \%$ of these occurring in developing countries [1]. In addition, one in three adults lives with one or more chronic conditions worldwide [2]. In the UAE, NCDs account for nearly $77 \%$ of all deaths, putting increasing strain on the well-being of the population, economic development and the health system [3]. As per the Emirate of Dubai law, it is mandatory that all residents have minimum health insurance coverage. In addition, all Emirati citizens, irrespective of sociodemographic characteristics, are eligible for healthcare services, whether in the UAE or overseas. Therefore, it is important to understand the determinants of chronic diseases to better allocate healthcare services and resources to individuals or groups who might be at higher risk among the Dubai population $[4,5]$. 
The causes of NCDs are multifactorial; these diseases may arise from a combination of underlying, modifiable and non-modifiable risk factors [6]. Research indicates that non-modifiable risk factors for NCDs include age, genetic predisposition, and ethnicity [7]. The presence of NCDs and many of their risk factors have been found to be more common in population groups with low income and low educational attainment in both low-middle income and high-income countries [8,9]. The relationship between sociodemographic characteristics and chronic conditions differs largely by geographic region [10]. Identifying the priority population groups that are the most affected by the growing burden of chronic diseases has become necessary to target appropriate health promotion and prevention programs.

Self-reported data are a critical component of all social science research and are frequently used in epidemiological research $[11,12]$. Although it is preferable to have measures of disease from medical records or objective measures, useful reports of disease status can be collected when interviewees selfreport their disease burden using surveys. In addition, many studies have argued that self-reports are reasonably accurate for certain chronic conditions and for routine screening exams [13]. Self-reports can provide a useful estimate for broad measures of population prevalence rates, especially when no detailed medical record data are available for those conditions $[13,14]$. The government of Dubai continues to monitor regularly population health. Therefore, the Dubai Health Authority conducted the Dubai Household Health Survey (DHHS) in 2019. The DHHS is a series of representative population surveys that have been carried out in 5-year intervals since 2009. The survey covers a wide range of health issues related to mortality, health expenditures, access to health services, health-related behaviors and other topics related to Dubai population health. To our knowledge, no studies investigating the effects of different sociodemographic characteristics on chronic morbidity are currently under research for the Emirate of Dubai. Therefore, this study aimed to contribute to the literature by examining the association between sociodemographic characteristics and chronic morbidity as reported among a representative sample of the Dubai population.

\section{Methods}

\section{Data source, study design}

The data were obtained from DHHS 2019, which was carried out between February and March 2019 as a collaborative work between the Dubai Health Authority (DHA) and Dubai Statistics Center (DSC). The DHHS is a cross-sectional complex study design, stratified by geographic area, and uses multistage probability sampling. The methods used in the survey are described in detail elsewhere [15]. The design and methodology of the survey were adopted from World Bank's Living Standards Measurement Surveys (LSMS), World Health Organization's Surveys (WHS) and the U.S. Centers for Disease Controls National Interview Surveys (NHIS). Of a total of 2,247 families, 9,630 individuals were interviewed with a response rate of $91.6 \%$. The sampling frame of the survey is all residents of Dubai. Each sector in Dubai is divided into areas, and each area is divided into blocks that are given a specific numerical identifier. The target population of this survey was Emirati and non-Emirati families. Sampling weights were used for this 
study to account for the complex survey design. Only adults aged 18+ were included in the final analysis (75.35\%).

\section{Variables and measures}

Sociodemographic variables were reported in weighted percentages: birth date, gender, marital status, nationality, educational attainment, and working status. Birth date was converted to four age groups as categorical and continuous variables. Gender was dichotomized to male and female. Marital status was categorized as married, unmarried, or others (divorced and widowed). Nationality was a categorical variable with 4 groups: Emirati, Asians[1], other Arabs[2], and other nationalities[3]. Educational attainment was a categorical variable with 3 groups and defined as less than secondary education, completed secondary school and tertiary education[4]. Throughout this manuscript, NCDs are referred to as self-reported chronic diseases and are defined as having or not having a chronic condition from a predefined list. Participants were asked if they ever had been diagnosed with one or more of the following chronic diseases: diabetes mellitus, high blood pressure, asthma, cancer, arthritis and mental or physical disabilities. Complete case analysis was considered in this study, and 17 missing chronic disease responses were excluded from the statistical analysis.

\section{Statistical analysis}

Categorical variables are reported in weighted frequencies and percentages, which were normalized to the total of the primary sampling unit. Chi-square tests for association in the survey data were used to investigate the association between chronic diseases (combined) and the independent variables [16]. Design-based versions of the Wilcoxon test and Kruskal-Wallis test were performed as appropriate. A multivariate logistic regression model for complex survey design was performed to investigate the influence of sociodemographic variables on chronic diseases. The quasi-binomial distribution was used as a binary outcome with reporting having a chronic disease or not. The predictors were age, nationality, marital status, gender, educational attainment, and work status. To evaluate the effect of age and marital status on self-reported chronic disease, an interaction term between age and marital status was added to the multivariate model and tested using the Rao-Scott test. The model with and without the interaction term showed that the interaction term adds a significant amount of information to the final multivariate model ( $p$-value=0.013). To compute interquartile range odds ratios (ORs) for age (years), age was divided by its interquartile range before it was added to the logistic regression models, and $95 \%$ confidence intervals (95\% Cls) were estimated [17]. All applied statistical tests were two-sided, and p-values $<0.05$ were considered significant. No adjustment for multiple comparisons was made. Statistical analyses were performed in $\mathrm{R}$ version 3.6.1 [18].

[1] All Asian nationalities other than Arabs.

[2] Any Arab nationalities other than Emirati (locals) 
[3] Any other nationalities not mentioned in the above categories.

[4] Postsecondary education (beyond high school, including undergraduate and graduate credentials)

\section{Results}

\section{Sociodemographic characteristics of the population of Dubai}

Overall, $15.01 \%$ of the surveyed population self-reported having at least one of the chronic morbidities on the predefined list in the survey during the past year. Figure 1 shows the distribution of age by gender, nationality, marital status and education group. Significant differences were observed among marital status, since unmarried individuals were younger than those who were married and others (divorced and widowed), $p$-value $<0.001$. Furthermore, significant differences were observed between the age distributions by education group, $p$-value $<0.001$. Table 1 illustrates the frequency distribution of sociodemographic characteristics among the Dubai population (aged 18+). Among the age groups, individuals aged $60+$ were most likely to have a chronic disease $(48.03 \%)$, p-value $<0.001$. Local Arabs (Emirati) reported the highest frequency of chronic diseases (25.14\%), p-value $<0.001$. Divorced and widowed individuals were most likely to report a chronic disease (34.21\%), p-value $<0.001$. Individuals who were not currently working reported a chronic disease more often than those who were working currently $(17.72 \%$ versus $11.39 \%$, respectively), $p$-value $<0.001$. Males and less-educated individuals reported a slightly higher frequency of chronic diseases, but the difference was not significant.

Table 1. Sociodemographic characteristics of the Dubai population with a self-reported chronic disease from the DHHS 2019. 


\begin{tabular}{|c|c|c|c|c|c|}
\hline \multirow[t]{2}{*}{ Variable } & \multirow[t]{2}{*}{ Categories } & \multicolumn{2}{|c|}{$\begin{array}{l}\text { Have a Chronic } \\
\text { Disease }\end{array}$} & \multirow[t]{2}{*}{$\begin{array}{l}\text { Wald's } \chi \square \text { TTest } \\
\text { (ndf) }\end{array}$} & \multirow[t]{2}{*}{ P-Value } \\
\hline & & No $(\%)$ & Yes (\%) & & \\
\hline \multirow[t]{4}{*}{ Age groups } & $18-24$ & 95.86 & 4.14 & \multirow[t]{4}{*}{$39.039(3)$} & \multirow[t]{4}{*}{$<0.0001$} \\
\hline & $25-44$ & 92.57 & 7.43 & & \\
\hline & $45-59$ & 71.86 & 28.14 & & \\
\hline & $60+$ & 51.97 & 48.03 & & \\
\hline \multirow[t]{2}{*}{ Gender } & Female & 89.29 & 10.71 & \multirow[b]{2}{*}{$3.396(\mathrm{df}=1)$} & \multirow[b]{2}{*}{0.067} \\
\hline & Male & 86.97 & 13.03 & & \\
\hline \multirow[t]{4}{*}{ Nationality } & Asian & 87.85 & 12.15 & \multirow[t]{4}{*}{$37.170(3)$} & \multirow[t]{4}{*}{$<0.0001$} \\
\hline & Local-Arab (Emirati) & 74.86 & 25.14 & & \\
\hline & Other Arabs & 90.25 & 9.75 & & \\
\hline & Other Nationalities & 90.06 & 9.94 & & \\
\hline \multirow[t]{3}{*}{ Marital Status } & Married & 85.25 & 14.75 & \multirow[t]{3}{*}{$32.423(2)$} & \multirow[t]{3}{*}{$<0.0001$} \\
\hline & Single & 94.78 & 5.22 & & \\
\hline & Others* & 65.79 & 34.21 & & \\
\hline \multirow[t]{3}{*}{$\begin{array}{l}\text { Educational } \\
\text { Attainment }\end{array}$} & $\begin{array}{l}\text { Less than secondary } \\
\text { education }\end{array}$ & 88.59 & 11.41 & \multirow[t]{3}{*}{$1.313(2)$} & \multirow[t]{3}{*}{0.271} \\
\hline & $\begin{array}{l}\text { Completed secondary } \\
\text { school }\end{array}$ & 88.27 & 11.73 & & \\
\hline & Tertiary education & 85.13 & 14.87 & & \\
\hline \multirow[t]{3}{*}{ Work Status } & Currently working & & & \multirow[t]{3}{*}{$18.332(1)$} & \multirow[t]{3}{*}{$<0.0001$} \\
\hline & & 88.61 & 11.39 & & \\
\hline & Currently not working & 827 & 1772 & & \\
\hline & otal & 84.99 & 15.01 & & \\
\hline
\end{tabular}

^SS; secondary school

* Others refers to formerly married or widowed and divorced individuals.

Wald's $\chi \square$ test corresponding numerator degrees of freedom (ndf) are listed in the table, while the denominator degrees of freedom was 201. 
Table 2 shows the results of the multivariate logistic regression model used to examine the factors associated with reporting of chronic disease. After adjusting for age, gender, marital status, and educational attainment, age (years) was the strongest predictor of chronic disease in the multivariate logistic regression IQR-OR = $3.6(95 \% \mathrm{Cl}: 2.8,4.7)$. Unmarried individuals reported fewer chronic diseases than married individuals (OR $0.11,95 \% \mathrm{Cl}: 0.02,0.70)$. However, older individuals who were unmarried were more likely to report a chronic disease compared to the reference group of older individuals who were married (OR $2.8,95 \% \mathrm{Cl}: 1.2,6.1)$. Emiratis were more likely to report a chronic disease than the reference group, Asians (OR 2.08, 95\% Cl: 1.62, 2.67). Males were more likely to report a chronic disease than females (OR 1.61, 95\% Cl: 1.277, 2.035).

Table 2. Multivariate logistic regression model for chronic disease among the Dubai Population from DHHS 2019

\begin{tabular}{|l|c|c|c|}
\hline \multicolumn{1}{|c|}{ Independent Variable } & Odds Ratio (95\% CI) & Wald's $\chi^{\text {口[ Test }}$ & P value \\
\hline Age & $3.6(2.8,4.7)$ & 90.32 & $<0.001$ \\
\hline Marital Status & & & \\
\hline Married & (Reference) & & \\
\hline Unmarried & $0.11(0.02,0.70)$ & 5.43 & 0.020 \\
\hline Others & $0.32(0.04,2.32)$ & 1.28 & 0.258 \\
\hline Nationality & & & \\
\hline Asians & (Reference) & & \\
\hline Local-Arab (Emirati) & $2.08(1.62,2.67)$ & 32.49 & $<0.001$ \\
\hline Non-Local (other Arabs) & $0.72(0.45,1.15)$ & 1.94 & 0.163 \\
\hline Other Nationalities & $0.81(0.56,1.18)$ & 1.19 & 0.275 \\
\hline Gender & & & \\
\hline Female & (Reference) & & \\
\hline Male & $1.61(1.28,2.04)$ & 16.107 & $<0.001$ \\
\hline Educational Attainment & & & \\
\hline Education tertiary education & (Reference) & & \\
\hline Education less than secondary school & $1.09(0.73,1.64)$ & 0.181 & 0.671 \\
\hline Completed secondary school & $1.18(0.80,1.74)$ & 0.69 & 0.407 \\
\hline Age and marital Status & & & \\
\hline Age \& married marital status & (Reference) & & \\
\hline Age \& unmarried marital status & $2.75(1.24,6.09)$ & 6.17 & 0.013 \\
\hline Age \& other marital status & $1.56(0.86,2.85)$ & 2.12 & 0.146 \\
\hline
\end{tabular}

Estimated odds ratios with 95\% confidence intervals and Wald's chi-square tests with one degree of freedom and their corresponding p-values. 


\section{Discussion}

In this article, we report a significantly high prevalence of self-reported chronic diseases (combined) among the adult population of the Emirate of Dubai, UAE. Furthermore, our results reveal that a number of non-modifiable risk factors are associated with chronic diseases in this population. The high crude prevalence $(15 \%)$ of chronic diseases found in this survey is in line with what has been reported previously across Arabian Gulf countries [19-22]. Because of logistical challenges, objective measures of chronic diseases did not provide adequate data for analysis. However, population-based self-reporting of chronic diseases has been shown to be relatively reliable [23]. Although non-communicable diseases are caused by a combination of modifiable and non-modifiable risk factors [24], our analysis was limited to non-modifiable risk factors. These characteristics are essential to understand the context, profile, and trend of non-communicable diseases among the population. Of the variables analyzed, age, gender, marital status, and nationality were found to be associated with self-reported chronic diseases as defined in our study methods.

As expected, older individuals were more likely to report higher levels of chronic diseases than younger individuals. Moreover, males were more likely to report chronic diseases than females. Since Dubai is a major metropolitan city [25], Emiratis were found to report a higher rate of chronic diseases than other nationalities in the Emirate. Interestingly, when combining age with marital status, an association was found between chronic disease and older individuals who remained unmarried, though not surprisingly. Our results confirmed that the prevalence of chronic conditions increases with age. Previous studies reported associations between sociodemographic characteristics and chronic diseases [9, 22, 26, 27]. Age has been found to be significantly associated with non-communicable diseases in many published studies in the UAE [27-29]. Other studies in the region have revealed similar findings related to the association of age with non-communicable diseases [19-21,30]. The explanation for this observation is the cumulative effect of non-communicable diseases over time as well as the degenerative process combined with aging leading to and contributing to the development of different types of chronic diseases.

Our results revealed that nationality is one of the non-modifiable risk factors and a predictor of the report of a chronic disease. This finding has been echoed in many studies, and sometimes nationality was referred to as ethnicity [31-34]. In this analysis, we found that Emiratis had a higher likelihood of reporting a chronic disease than other nationalities when adjusting for other sociodemographic characteristics. Another study that examined diabetes and impaired fasting glycemia in the UAE revealed that these conditions were higher in Emiratis than in other nationalities [32]. Similarly, for cardiovascular diseases, a study has found that these morbidities are more prevalent in some nationalities and ethnicities than others [33]. These findings could be due to lifestyle, genetics, cultural and/or socioeconomic factors as explained elsewhere [35].

Gender was found to be another significant predictor for chronic diseases among the representative sample of DHSS 2019. Different studies have examined the gender difference in non-communicable 
diseases and the experience of these illnesses related to gender identity [35-38]. It is worth noting that the nature of chronic diseases differs by gender. Men are more prone to a wider range of health risks, such as hypertension, cerebrovascular disease and cardiovascular diseases [39]. On the other hand, women are more likely to report diseases related to arthritis, osteoporosis diabetes and hypertension [40]. Moreover, since men tend to adopt unhealthy behaviors, such as smoking and alcohol consumption, they are more likely to report experiencing chronic disease and poor health [35, 39].

In the current study, unmarried adults were reported to have a lower risk of chronic diseases than married and formerly married adults. However, when combining age with marital status, the relationship was reversed, and chronic disease was higher in older unmarried individuals within our population sample. Unmarried individuals who were older had a three-fold risk of reporting a chronic disease compared to older married individuals. Although published data show that, the association between chronic diseases and marital status is scarce and old [41-43], there are many published results demonstrating higher risk of mortality among unmarried individuals [44-46]. Moreover, a longitudinal study in the United States identified that marital status was associated with poor health outcomes at the oldest ages [47]. This association can be attributed to the selective effect of marriage, where marriage can sometimes reduce stress and provide social support in light of clarity in the defined roles between married couples.

It is important to acknowledge some limitations of our study. The data on having a chronic disease or not available for this study derived from individual self-reports and not from medical records. Although selfreporting is a widely used practice to reflect patient experience, it may include subjectivity as a diagnostic tool with bias and accuracy. Self-reporting might lead to under- or over reporting on some occasions. Another limitation involved in this study, the severity of the chronic disease and the existence of comorbidity were not included, and these qualifiers may better explain the status of individuals. While the DHHS was limited to the population of Dubai, we cannot generalize the results to the general population of the UAE. However, the availability of the data can be used as a strength, especially because the survey tool is valid and was conducted through well-trained surveyors. Additionally, the data can be used in the future to conduct trend and pattern analyses for monitoring Dubai population health.

\section{Conclusion}

In conclusion, the results of this study, with a substantially large sample size, provide important NCD data for the population of Dubai and indeed contribute to limited empirical research in the emirate of Dubai. Our results demonstrated that older age, unmarried status, male, and Emirati nationality are significant predictors of NCDs. Understanding the dynamics of age, ethnicity and gender and their association with NCDs can help to inform and be desirable for priority health interventions. The current findings could be translated to policies and strategies to reallocate healthcare services to create more effective health prevention and promotion programs. This process includes improving the quality of current programs or initiating new programs related to the targeted population. In the future, it is important to conduct indepth assessments of patients' quality of life and experience with chronic conditions to reduce the complications associated with NCDs. 


\section{List Of Abbreviations}

DHA: Dubai Health Authority, DHHS: The Dubai Household Health Survey, DSC: Dubai Statistics Center, WHO: World Health Organization, NCDs: Non-Communicable Diseases.

\section{Declarations}

\section{Ethics approval and consent to participate}

Ethical standards were adhered throughout this study as per Dubai Health Authority guidelines and regulations. We confirm that the study is not an experimental study. As per Dubai Health Authority and Dubai Scientific Research Ethics Committee guideline, the consent form was waived and the study was defined as nonhuman subject research.

\section{Consent for participation}

Not applicable

\section{Availability of data and materials}

The data that support the findings of this study are from the Dubai Health Authority. However, restrictions apply to the availability of these data; thus, these data are not publicly available. Data are available from the corresponding author upon responsible request with permission from the Dubai Health Authority.

\section{Competing interests}

The authors declare that they have no competing interests.

\section{Funding}

This research paper did not receive any specific grant from funding agencies in the public, commercial or nonprofit sectors.

\section{Author contributions}

W.A. designed the study and drafted the manuscript. H.M. assisted in writing and reviewing the manuscript. H.H. assisted in writing and reviewing the manuscript. G.S. reviewed the statistical analysis. A. S. A. performed the statistical analysis, interpreted the results, and edited the manuscript. R.A. reviewed the manuscript. A.A. designed the study and revised the manuscript

\section{Acknowledgments}

The research team would like to express their appreciation and gratitude to the team of Dubai Statistics Centre for their significant contribution to the Household Health Survey. 


\section{References}

1. World Health Organization. Noncommunicable diseases country profiles. World Health Organization. 2018. http://www.who.int/nmh/publications/ncd-profiles-2018/en/. Accessed 10 Oct 2018.

2. Hajat C, Stein E. The global burden of multiple chronic conditions: a narrative review. Prev Med Rep. 2018;12:284-93.

3. Riley L, Cowan M. World Health Organization noncommunicable diseases country profiles. Geneva, Switzerland: WHO Library Cataloguing-in-Publication Data; 2014.

4. Alnakhi WK, Segal JB, Frick KD, Hussin A, Ahmed S, Morlock L. Treatment destinations and visit frequencies for patients seeking medical treatment overseas from the United Arab Emirates: results from Dubai Health Authority reporting during 2009-2016. Trop Dis Travel Med Vaccines. 2019;5:10.

5. Mayosi BM, Flisher AJ, Lalloo UG, Sitas F, Tollman SM, Bradshaw D. The burden of noncommunicable diseases in South Africa. Lancet. 2009;374:934-47.

6. Allen L. Are we facing a noncommunicable disease pandemic? J Epidemiol Glob Health. 2017;7:5-9.

7. Hosseinpoor AR, Bergen N, Kunst A, Harper S, Guthold R, Rekve D, et al. Socioeconomic inequalities in risk factors for non communicable diseases in low-income and middle-income countries: results from the World Health Survey. BMC Public Health. 2012;12:912.

8. van Zyl S, van der Merwe LJ, Walsh CM, Groenewald AJ, van Rooyen FC. Risk-factor profiles for chronic diseases of lifestyle and metabolic syndrome in an urban and rural setting in South Africa. Afr J Prim Health Care Fam Med. 2012;4:346.

9. Afshar S, Roderick PJ, Kowal P, Dimitrov BD, Hill AG. Multimorbidity and the inequalities of global ageing: a cross-sectional study of 28 countries using the World Health Surveys. BMC Public Health. 2015;15:776.

10. Skinner KM, Miller DR, Lincoln E, Lee A, Kazis LE. Concordance between respondent self-reports and medical records for chronic conditions: experience from the Veterans Health Study. J Ambul Care Manage. 2005;28:102-10.

11. Smith TC, Smith B, Jacobson IG, Corbeil TE, Ryan MA. Reliability of standard health assessment instruments in a large, population-based cohort study. Ann Epidemiol. 2007;17:525-32.

12. Martin LM, Leff M, Calonge N, Garrett C, Nelson DE. Validation of self-reported chronic conditions and health services in a managed care population. Am J Prev Med. 2000;18:215-8.

13. Comino EJ, Tran DT, Haas M, Flack J, Jalaludin B, Jorm L, et al. Validating self-report of diabetes use by participants in the 45 and up study: a record linkage study. BMC Health Serv Res. 2013;13:481.

14. Dunstan DW, Zimmet PZ, Welborn TA, Cameron AJ, Shaw J, de Courten M, et al. The Australian diabetes, obesity and lifestyle study (AusDiab)-methods and response rates. Diabetes Res Clin Pract. 2002;57:119-29.

15. Dubai Health Authority, Dubai Household Health Survey. 2019.

https://www.dha.gov.ae/Documents/opendata/English_DDHS.pdf. Accessed 20 Nov 2020. 
16. Rao JNK, Scott AJ. On chi-squared tests for multiway contingency tables with cell proportions estimated from survey data. Ann Stat. 1984;12:46-60.

17. Koch GG, Freeman DH, Freeman JL. Strategies in the multivariate analysis of data from complex surveys. Int Stat Rev. 1975;43:59-78.

18. R Core Team. R: a language and environment for statistical computing. Vienna, Austria: R Foundation for Statistical Computing; 2019.

19. Al-Mawali A, Jayapal SK, Morsi M, Al-Shekaili W, Pinto AD, Al-Kharusi H, et al. Prevalence of risk factors of non-communicable diseases in the sultanate of Oman: STEPS survey 2017. 2020; doi:10.21203/rs.2.0937/v1.

20. Badr H, Maktabi MA, Al-Kandari M, Sibai AM. Review of non-communicable disease research activity in Kuwait: where is the evidence for the best practice? Ann Glob Health. 2019;85:45.

21. Hamadeh RR. Noncommunicable diseases among the Bahraini population: a review. East Mediterr Health J. 2000;6:1091-7.

22. Radwan H, Ballout RA, Hasan H, Lessan N, Karavetian M, Rizk R. The epidemiology and economic burden of obesity and related cardiometabolic disorders in the United Arab Emirates: a systematic review and qualitative synthesis. J Obes. 2018;2018:2185942.

23. Najafi F, Moradinazar M, Hamzeh B, Rezaeian S. The reliability of self-reporting chronic diseases: how reliable is the result of population-based cohort studies. J Prev Med Hyg. 2019;60:E349-53.

24. Manning K, Senekal M, Harbron J. Non-communicable disease risk factors and treatment preference of obese patients in Cape Town. Afr J Prim Health Care Fam Med. 2016;8:e1-e12.

25. Dubai Economic Report. 2018. http://www.dubaided.ae/StudiesAndResearchDocument/DubaiEconomic-Report-2018-Full-Report.pdf. Accessed 15 Apr 2020

26. El-Shahat YI, Bakir SZ, Farjou N, Hashim T, Bohaliga A, Al-Hossani H, et al. Hypertension in UAE citizens - preliminary results of a prospective study. Saudi J Kidney Dis Transpl. 1999;10:376-81.

27. Shah SM, Loney T, Sheek-Hussein M, El Sadig M, Al Dhaheri S, El Barazi I, et al. Hypertension prevalence, awareness, treatment, and control, in male South Asian immigrants in the United Arab Emirates: a cross-sectional study. BMC Cardiovasc Disord. 2015;15:30.

28. Alawadi F, Hassanein M, Suliman E, Hussain HY, Mamdouh H, Ibrahim G, et al. The prevalence of diabetes and pre-diabetes among the Dubai population: findings from Dubai household health surveys, 2014 and 2017. Dubai Diabetes Endocrinol J. 2020;26:78-84.

29. Sulaiman N, Albadawi S, Abusnana S, Mairghani M, Hussein A, Al Awadi F, et al. High prevalence of diabetes among migrants in the United Arab Emirates using a cross-sectional survey. Sci Rep. 2018;8:6862.

30. Mahmood FM. Prevalence and prevention of lifestyle-related diseases in Saudi Arabia. Int J Health Sci (Qassim). 2018;12:1-2.

31. Ong ME, Shin SD, De Souza NN, Tanaka H, Nishiuchi T, Song KJ, et al. Outcomes for out-of-hospital cardiac arrests across 7 countries in Asia: the Pan Asian Resuscitation Outcomes Study (PAROS). 
Resuscitation. 2015;96:100-8.

32. Malik M, Bakir A, Saab BA, King H. Glucose intolerance and associated factors in the multi-ethnic population of the United Arab Emirates: results of a national survey. Diabetes Res Clin Pract. 2005;69:188-95.

33. Balfour PC, Jr., Rodriguez CJ, Ferdinand KC. The role of hypertension in race-ethnic disparities in cardiovascular disease. Curr Cardiovasc Risk Rep. 2015;9:18.

34. O'Loughlin J. Understanding the role of ethnicity in chronic disease: a challenge for the new millennium. CMAJ. 1999;161:152-3.

35. Strauss J, Gertler PJ, Rahman O, Fox K. Gender and life-cycle differentials in the patterns and determinants of adult health. J Hum Resour. 1993;28:791-837.

36. Charmaz K. Identity dilemmas of chronically ill men. Sociol Q. 1994;35:269-88.

37. Traynor V. One world, one future. Elder Care. 1998;10:12.

38. Babwah F, Baksh S, Blake L, Cupid-Thuesday J, Hosein I, Sookhai A, et al. The role of gender in compliance and attendance at an outpatient clinic for type 2 diabetes mellitus in Trinidad. Rev Panam Salud Publica. 2006;19:79-84.

39. Bird CE, Rieker PP. Gender matters: an integrated model for understanding men's and women's health. Soc Sci Med. 1999;48:745-55.

40. Senanayake P. Women and reproductive health in a graying world. Int J Gynaecol Obstet. 2000;70:5967.

41. Joung IM, van de Mheen H, Stronks K, van Poppel FW, Mackenbach JP. Differences in self-reported morbidity by marital status and by living arrangement. Int J Epidemiol. 1994;23:91-7.

42. Verbrugge, Lois M. Marital Status and Health. J Marriage Fam. 1979;41: 267-85. JSTOR, www.jstor.org/stable/351696.

43. Franke S, Kulu H. Mortality differences by partnership status in England and Wales: the effect of living arrangements or health selection? Eur J Popul. 2018;34:87-118.

44. Goldman N, Korenman S, Weinstein R. Marital status and health among the elderly. Soc Sci Med. 1995;40:1717-30.

45. Rendall MS, Weden MM, Favreault MM, Waldron $\mathrm{H}$. The protective effect of marriage for survival: a review and update. Demography. 2011;48:481-506.

46. Zueras P, Rutigliano R, Trias-Llimós S. Marital status, living arrangements, and mortality in middle and older age in Europe. Int J Public Health. 2020;65:627-36.

47. Bauer UE, Briss PA, Goodman RA, Bowman BA. Prevention of chronic disease in the 21st century: elimination of the leading preventable causes of premature death and disability in the USA. Lancet. 2014;384:45-52.

\section{Figures}



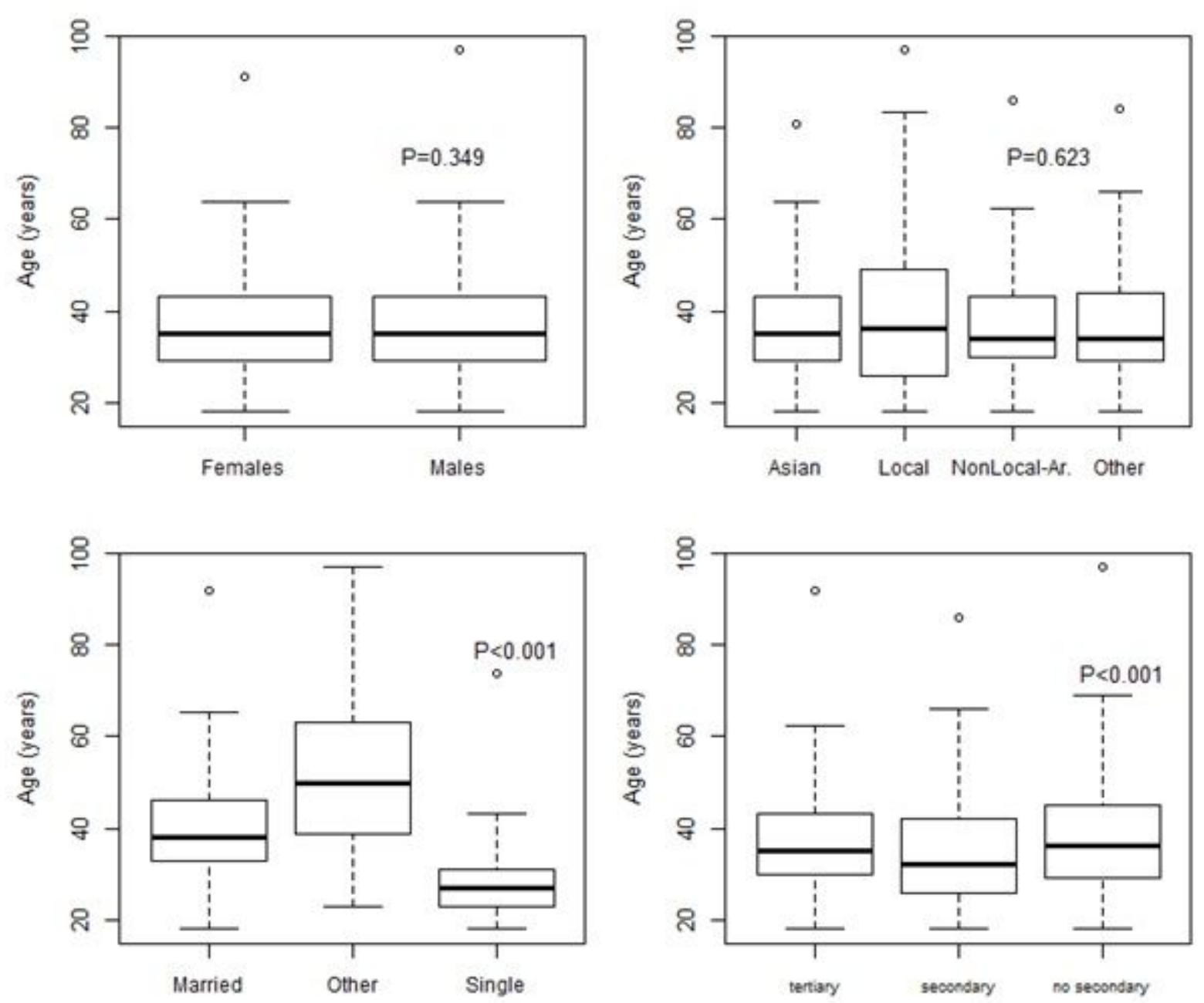

Figure 1

Distribution of Age by Gender, Nationality, Marital Status and Education Groups. 